\title{
Using Eye Tracking to Trace a Cognitive Process: Gaze Behaviour During Decision Making in a Natural Environment
}

\author{
Kerstin Gidlöf \\ Lund University
}

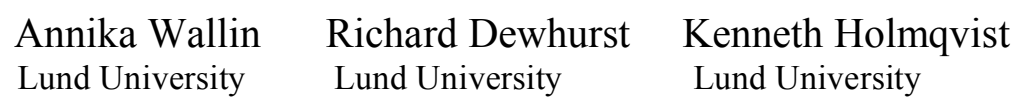

The visual behaviour of consumers buying (or searching for) products in a supermarket was measured and used to analyse the stages of their decision process. Traditionally metrics used to trace decision-making processes are difficult to use in natural environments that often contain many options and unstructured information. Unlike previous attempts in this direction (i.e. Russo \& Leclerc, 1994), our methodology reveals differences between a decision-making task and a search task. In particular the second (evaluation) stage of a decision task contains more re-dwells than the second stage of a comparable search task. This study addresses the growing concern of taking eye movement research from the laboratory into the 'real-world', so findings can be better generalised to natural situations.

Keywords: eye movements, decision-making, visual search, process tracing, natural environments

\section{Introduction}

The advent of more sophisticated mobile eye-tracking equipment has lead in recent years to a growth of research into the deployment of visual attention and eye movements in natural environments. Car driving (Shinoda, Hayhoe \& Shrivastava, 2001), playing cricket (Land \& McLeod, 2000), walking (Jovanevic-Misic \& Hayhoe, 2009), and the everyday task of making a cup of tea (Land, Mennie \& Rusted, 1999), all require the tight coordination of attentional, cognitive, and motor abilities. Despite the research amassed from laboratory settings (e.g. Findlay, Brown \& Gilchrist, 2001; McSorley \& Findlay, 2003; Mulckhuyse, Van Zoest \& Theeuwes, 2008; Born, Kerzel \& Theeuwes, 2011), it is evident that the mechanisms of attentional deployment differ considerably in the lab compared to the real-world (e.g. Hayhoe \& Ballard, 2005; Smilek, Eastwood, Reynolds \& Kingstone, 2007; Kingstone, Smilek, Eastwood, 2008; Foulsham, Walker \& Kingstone, 2011). Although we know from the seminal studies of Yarbus (1967), and more recent laboratory based work (e.g. Castelhano, Mack, \& Henderson, 2009), that eye movements are highly task dependent and are linked to our cognitive goals, research is yet to uncover the eye movement repertoires associated with higher level tasks we encounter on a day-to-day basis. One such avenue is decision making. Almost all decisions we make involve acquisition of visual information but decision-making is a special kind of task where the information is valued very differently in each case. For each case, the kind of information needed to complete the task might differ largely due to different preferences or goals. One piece of information might be crucial for one person but not at all interesting to another. This calls for a new set of eye tracking measures that can be used to compare one cognitive process to another without relying on exactly what is being visually attended to. A prime example of the many choices we make in everyday life is the supermarket, and this setting provides the ideal scenario to investigate the eye-movement repertoires of decision-making in the real world. This is the focus of this paper. 
Journal of Eye Movement Research

$6(1): 3,1-14$

Two strands of research in decision-making form the backdrop of the current paper, and shed light upon its aims. First, the decision-making literature has incorporated eye movement recordings previously (e.g. Glaholt \& Reingold, 2009, 2011; Glaholt, Wu, \& Reingold, 2010; Krajbich, Armel and Rangel, 2010; Krajbich \& Rangel, 2011; Schotter, Berry, McKenzie \& Rayner, 2010; Simion \& Shimojo, 2006; Wedell \& Senter, 1997). These investigations focus on how eye movements unfold over the course of the decision process and specifically on attentional shifts towards the chosen object. Second, while the above-mentioned research tap into the decision making process, it does not focus specifically on how information is acquired and integrated. Russo and Leclerc (1994) have tackled this avenue with eye tracking, suggesting that this methodology allows more valid identification of functional stages in the decision process than simple time-based divisions which have been previously employed (Bettman \& Park, 1980).

For the present investigation, we sought to study consumers' decision making in its natural context: the supermarket. We aim to uncover the timeline of gaze behaviour in a decision-making task and to device a model of the decision making process based on this information. In the following sections we will review process tracing research, leading up to modern experiments with eye tracking. We will then consider eye tracking research specifically on consumer choices in store. Based on this evaluation we will then outline our own approach, which attempts to bring together the eye tracking research performed in natural environments with the attempts to trace the decision-making process.

\section{Process tracing in decision-making}

The field of judgment and decision-making has a history of process tracing since at least the seventies (e.g. Payne, Braunstein \& Carroll, 1978; Ford, Schmitt, Schechtman, Hults \& Doherty, 1986; Payne, Bettman \& Johnsson, 1993; Reisen, Hoffrage \& Mast, 2008), but eye-tracking technology has been used only recently. Traditionally, decision-making processes are traced using methods of verbal reports (e.g. Bettman \& Park, 1980), as well as information boards (e.g. Payne, 1976). Mouse Lab (Payne, Bettman \& Johnson 1988) is a more up-todate adaptation of information boards - basically this software is a computerized information board that permits information about different options contained in a matrix to become visible upon hovering the mouse over
Gidlöf, K., Wallin, A., Dewhurst, R. \& Holmqvist, K. (2013) Gaze Behaviour During Decision Making in a Natural Environment

that option. This is intended to mimic the cost of information acquisition and limited simultaneous access to attributes values in the real world.

However, the environments mentioned above represent a fundamentally different decision environment than for example a supermarket. First, the number of options presented in Mouse Lab is constrained by what can be made visible on a computer screen (typically between 28 options). In contrast, the Food and Marketing Institute states that the average number of items carried in a regular supermarket in the United States 2010 was 38718 . For the product category used in the current study (conducted in Sweden) participants chose between 90 options. Second, whereas information boards structure options and their attributes in rows and columns, the options available in the supermarket often differ in how information about the attributes are organized. Moreover, the information can be hard to find, and may not be available for all options. Since the number of options affects choice quality, consumer satisfaction and experienced difficulty (e.g., Chernev, 2003; Iyengar \& Lepper, 2000; Malhotra, 1982; Reutskaja \& Hogarth, 2005; Shah \& Wolford, 2007), and the structure and format of the decision environment influences consumer information acquisition (e.g., van Raaij, 1977), it is of vital importance to investigate the external validity of previous research.

\section{Process tracing with eye tracking}

In approximately the last 5 seconds leading up to a response (a choice) one can observe a bias in the looking behaviour of participants towards the item that is finally chosen. This bias is greatest around 2 seconds before selection, and has been coined the Gaze Cascade Effect (Shimojo, Simion, Shimojo \& Scheier, 2003), representing a positive feedback loop between what we look at and what we prefer. For the present paper, this is important for two reasons.

First, it suggests that from the first time we fixate the item we finally chose it will thereafter receive more and more attention. This means that there is some justification for using the first time the chosen item is looked at as a cut-off for when the initial overview screening ends and an evaluation phase begins. Secondly, Glaholt and Reingold (2011) conclude that a strict version of the gaze cascade model is not entirely valid, and that the results fit best into a framework where dwell duration reflects an early screening process encoding potential alternatives, 
Journal of Eye Movement Research

$6(1): 3,1-14$

while the bias in dwell frequency nearer the decision reflects a later stage of evaluation comparing between alternatives.

Several other studies have also used eye tracking to investigate decision-making. Some focus on identifying aspects of the process underlying the choice, in particular how information is acquired and integrated and how decisions are based on the integrated information (van Raaij, 1977; Russo \& Leclerc, 1994; Russo \& Rosen, 1975). Others focus on consumers' visual attention to products in various shelf layouts (e.g. Chandon, Hutchinson, Bradlow \& Young, 2009) and under different time constraints and motivational conditions (e.g. Pieters and Warlop, 1999). However, none of these studies, including the gaze cascade research, are performed in a natural environment.

\section{Eye tracking and process tracing in a natural environment}

Since we are interested in tracing decisions in the natural environment we are particularly interested in studies that have used a methodology that is applicable in these contexts. Here Russo and Leclerc (1994) stand out since they used eye tracking to study different stages of the decision process with naturalistic product stimuli, albeit in a 'prototypical store'. As we have seen, the identification of stages is promising for uncovering the cognitive processes underlying decisions. Moreover, in the context of a store, stages allow us to compare participants that vary in how they evaluate and approach the same aspects of the visual environment: a product that is suitable and interesting for one participant may not be so for another, yet if the same stages are used we can identify their selection strategies.

In Russo and Leclerc's (1994) study, participants made decisions among real products presented on a shelf in the laboratory. These researchers argue that their data demonstrates three stages of the decision process: orientation, evaluation and verification. During the orienting stage the participants attained an overview of the options available by a series of fixations on single options. This stage was concluded by the first re-fixation on an option. Then followed the evaluation stage, which consists of comparisons between different options, and is characterized by re-fixations. This stage terminates upon a selection being made. The verification stage directly afterwards resembled the orienting stage, with a series of
Gidlöf, K., Wallin, A., Dewhurst, R. \& Holmqvist, K. (2013) Gaze Behaviour During Decision Making in a Natural Environment fixations on single options, but this time their role was not overview scanning but to validate the choice that had been made. Glaholt and Reingold's (2011) work outlined above is in keeping with these conceptual stages; indeed their conclusions of initial screening followed by later evaluation fit into this structure. However, there are a number of problems with Russo and Leclerc's (1994) implementation. First, they did not compare their decision data with similar tasks that did not involve decisions. Thus, we do not know if the stages observed are unique to the decision process, or reflect search in general. There have indeed been attempts to divide a visual search process into stages (Malcolm \& Henderson, 2009, 2010) with stages separating search initiation, scanning time and verification time. However, as pointed out by Foulsham and Kingstone (2012), these stages may not be useful in the real world where targets are often not in the visual field at the onset of search. Similarly, the idea of dividing a cognitive process into different functional stages has also been applied to problem solving, where the first stage can be viewed as search, the second as comparison, and the third stage as confirmation (see Just \& Carpenter, 1985). Secondly, although it is good to have a cut-off in the eye movement record for commencement of the second stage, the theoretical motivation for this segmentation is questionable. Russo and Leclerc (1994) argue that the first re-fixation signifies that viable options have been scanned and thereafter are compared. However, re-fixations do not necessarily have this function. An item could be re-inspected because it was forgotten, or because it was not fully encoded the first time around and the participant returns to complete processing (Gilchrist \& Harvey, 2000). Either way such cases would not constitute evaluation, but would be classified as such according to Russo and Leclerc's (1994) division. A less coarse segmentation would clearly be useful.

Despite the efforts made to create a testing situation, which more closely resembled the actual shopping experience, like the experiments testing the gaze cascade effect covered above, Russo and Leclerc's (1994) stimuli and set-up deviates in several important ways from decision making in the natural environment of the supermarket. As already noted it was a "prototypical store"; basically a shelf containing 16 items where the layout and spacing was fundamentally different from what we encounter during a weekly shop. Each item represented a unique choice (there were not several packages of the same product) and the items were spatially separated in 
Journal of Eye Movement Research

$6(1): 3,1-14$

order to facilitate tracking participants' gaze. Visual search is performed more easily in such an environment than in the crowded shelves the supermarket. In addition, participants did not make a real choice in the sense that they had to select a product to pay for, take home and consume.

\section{Natural Decision Segmentation Model}

How does the process of making a decision influence eye movements in the natural setting of the supermarket? What can these eye movements tell us about how decision-making proceeds? As we have seen the decisionmaking and eye movement literature is yet to broach the gap towards the shift to Cognitive Ethology which others have initiated with eye tracking in the real world (e.g. Foulsham, Walker, Kingstone, 2011; Kingstone, Smilek, Eastwood 2008). The aim of the present paper is therefore to gain further knowledge in the realtion between consumers' visual attention during choice and their decision processes in the natural environment of the supermarket.

Here we compare the processes decision-making in store, with the processes of performing a visual search task on the same product shelf. Visual search and decision-making in this context share many common properties: both require the matching of target templates held in working memory, and the ability to inhibit distractors not matching the target's visual characteristics (cf. Duncan \& Humphreys, 1989; Treisman \& Gormican, 1988). However, whereas in visual search a unique target template is set from the outset, in decision-making the item looked for is updated based on on-going visual input and associated cognitive processing.

Research on visual search has demonstrated that the eye movements in a visual search task are highly dependent on the organization of the search array with an increase in fixation duration and the number of fixations as the display becomes more complex (Vlaskamp \& Hooge, 2006). The supermarket shelf presents consumers with a highly complex array of items, where the search is impeded by the similarity between target and non-target items and a large variation in non-targets. The perception of peripherally viewed items is also highly likely to be impaired by visual crowding effects.

In our approach we therefore compare a situation where participants search for a particular product to a situation where they select a product of their choice from
Gidlöf, K., Wallin, A., Dewhurst, R. \& Holmqvist, K. (2013) Gaze Behaviour During Decision Making in a Natural Environment amongst different alternatives. In this way we are able to assess the generality of stage-based approaches like Russo and Leclerc's (1994).

Thus, we used the stages proposed by Russo and Leclerc (1994) to identify decision-making in a natural environment. However, because of the problems of delineating the first and second stage based simply on the first re-fixation, we also put forward an alternative method for splitting up the stages based on the process tracing literature with eye tracking, the Natural Decision Segmentation Model. As the gaze cascade model demonstrates, that following the first fixation on the selected item it cumulatively receives more attention until it is eventually chosen, we used the time the chosen item is first fixated as a cut-off for when the initial overview screening ends and the evaluation phase begins. This goes some way to eliminating re-fixations, which occur for reasons other than evaluating between alternatives (such as to complete insufficient processing on the first visit). The Natural Decision Segmentation Model differs from Russo and Leclerc (1994) in that its evaluation phase is more narrowly defined. This is important since this arguably is the stage that will differentiate decisionmaking from other cognitive processes, such as search behaviour. Furthermore, we permit re-dwells in all stages and can thus use them to achieve more information about how the stages develop over time, and possibly about task difficulty (given the role of re-fixations discussed by Gilchrist and Harvey, 2000). The different division of the stages are displayed in figure 1.

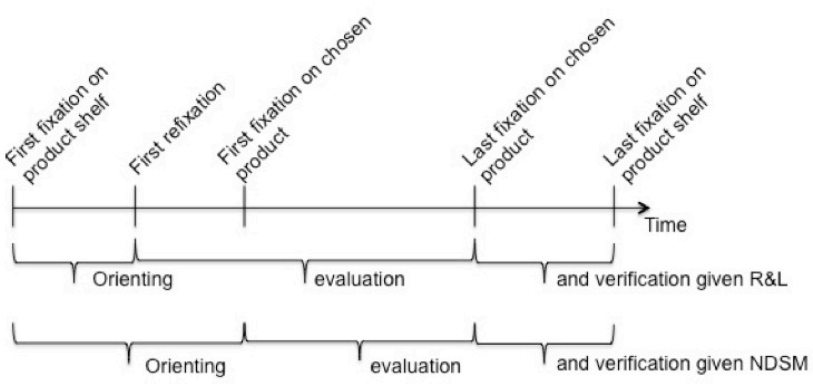

Figure 1. The decision process

However, models like these will always be rough sketches of the process and different stages are impossible to separate in a clear-cut fashion. Our interpretation of the model is that each stage is dominated by a specific function of the decision process but is may also contain elements of other stages. E.g. there can be orienting also 
Journal of Eye Movement Research

$6(1): 3,1-14$

in the evaluation stage but this second stage will still be dominated by an evaluation behaviour.

It is predicted that the three stages of the decision process (orientation, evaluation, and verification) can be identified with both Russo and Leclerc's (1994) and the Natural Decision Segmentation Model in the natural environment of the supermarket, but that our division will better capture the difference between them. Moreover, we expect that the Natural Decision Segmentation Model will be more effective in differentiating a search process from a decision process because it more validly restricts gaze which is counted as orienting (i.e. search-like) and gaze which is evaluative (i.e. decision-like).

In line with this, we expect the same stages to be present in both the search and decision tasks but the deployment of visual attention through the stages is expected to differ. The stage that should maximally differentiate search and decision tasks is the evaluation stage, since both the orienting stage and the verification stage are likely to be present also when searching for a product. The evaluation stage is aimed at comparing different products, and should be much reduced in the search task.

\section{Method}

\section{Participants}

In this field study we obtained complete, good quality eye tracking data from 40 participants, a substantial amount given the difficulties associated with illumination and reflexes from participants' glasses in the natural environment, outside of the laboratory. All participants were Swedish-speaking with normal or corrected to normal vision. Participants were recruited in the supermarket and reimbursed with a gift check of SEK50. This check would cover all pasta purchases (mean price of pasta package $=$ SEK 17, max price $=$ SEK37) but could also be used for any purchase in the supermarket. 25 participants performed the decision task and 15 participants performed the search task. All participants were randomly assigned to one of the two tasks.

\section{Stimuli}

The stimuli consisted of all products in the pasta section offered by the supermarket in which the study took place, which amounted to 90 different options distributed over 13 brands. The pasta was distributed over two
Gidlöf, K., Wallin, A., Dewhurst, R. \& Holmqvist, K. (2013) Gaze Behaviour During Decision Making in a Natural Environment shelves on each side of an aisle (see figure 2). The pasta category was chosen for several reasons. First, this is a repeat purchase product. Second, the frequency of purchase is considered to be large enough that most consumers are quite familiar with the category.
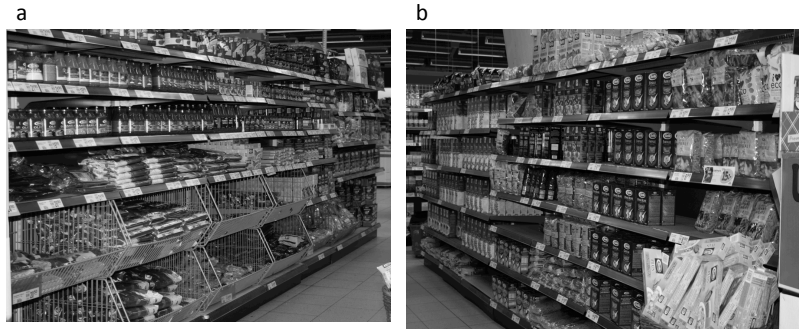

c

d
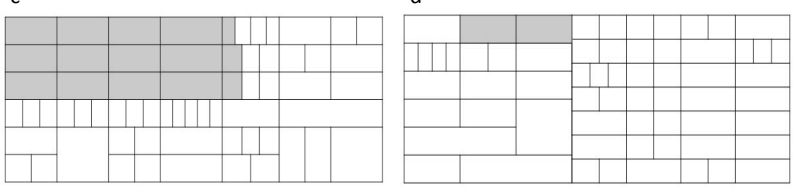

Figure2. The shelves used in the study. Panels $a$ and $b$ show photos of the shelves on both sides of the aisle, panels $c$ and $d$ schematic drawings of the same shelves. The grey areas in panel $c$ and $d$ contain non-pasta products

\section{Apparatus}

Participants were fitted with a wireless SMI iViewX HED-video based pupil and corneal reflex system, recording data at $50 \mathrm{~Hz}$ and scene video at $25 \mathrm{~Hz}$ with overlaid gaze cursor. The system consists of two cameras mounted on a helmet that records both the eye movements of the participant and the scene on which the participant is looking.

\section{Procedure}

Before entering the supermarket, the eye tracker was calibrated on the participants' right eye using a distance estimated to be natural for standing in front of a product shelf (at arm's length).

After the calibration process, each participant was asked to do either a search task or a decision task. For the search task participants were asked to go the pasta shelf, find a specific pasta (specified in the instructions) and return it to the research assistant. All participants were asked to find the same pasta. For the decision task participants were asked to buy a pasta product of their choice and proceed with their shopping. 10 participants who performed the decision task also did an additional, unrelated task before the decision. However, these partici- 
Journal of Eye Movement Research

$6(1): 3,1-14$

pants did not differ significantly from the rest of the group on any of the dependent measures, and we will not treat them separately.

\section{Analysis}

The eye tracking recordings from each participant were coded manually using the video player functionality in the analysing software SMI BeGaze. For each participant, the number, duration and order of dwells was coded for each product in the pasta category. A dwell was defined as a gaze staying on one product for at least $120 \mathrm{~ms}$. A dwell is a collection of one or several fixations within a certain area of interest (in this case a product in the display), from entry to exit.

To identify the different stages in the decision process we divided the eye tracking data into stages using two different approaches. The first approach was similar to the one used by Russo and Leclerc (1994) with some exceptions.

In Russo and Leclerc (1994), Stage 1 was defined as all dwells before but not including the first re-dwell on a product, and stage 2 as all dwells between the first redwell on a product and the announcement of the decision. Since it is difficult to know exactly when the decision is made in this natural setting (participants were not asked to verbally announce their choice), we instead defined stage 2 as all dwells between the first re-dwell up to the last dwell on the chosen product. With the last dwell on the chosen product we conclude that participants were satisfied enough with the information acquired from this product in order to chose it. This alteration also made stage 3, as defined by Russo and Leclerc (1994) impossible to detect since our participants did not verbally announce their choices. Thus, stage 3 consisted of all dwells after the last dwell on the chosen product.

In the Natural Decision Segmentation Model, we focused on the separation of the first two stages. Our concern was that in this natural environment, abundant in options, the orienting stage is more challenging, and ending it at the first re-dwell is too conservative. Russo and Leclerc (1994) also rely on a specific functional, evaluative role of the re-fixations that is not self-evident. Re-fixation of an item can simply mean that the participant has forgotten that the item has been fixated, or that the fixated item was not fully processed before the participant removed the gaze and therefore returned to complete processing (Gilchrist \& Harvey, 2000). Therefore,
Gidlöf, K., Wallin, A., Dewhurst, R. \& Holmqvist, K. (2013) Gaze Behaviour During Decision Making in a Natural Environment we define stage 1 as all dwells leading up to, but not including the first dwell on the chosen product. Using this definition we can make sure that at the end of stage 1, consumers have oriented themselves towards a region of the shelf where they can find interesting options. Stage 2 was defined as all dwells between the first and the last dwell on the chosen product. Stage 3 was the same for both approaches and consisted of all dwells after the last dwell on the chosen product. With this division of the stages it is also possible to study how the re-dwells are used throughout the process since they are not only present in the second stage.

\section{Results}

The results of this study are presented in two sections. First, we examined the amount of information acquired in the search task and in the decision task respectively. In the second section, we examined the underlying processes of the two tasks by dividing the eye tracking data into stages.

\section{Amount of information}

For an overview of the information acquired in the two tasks, some general eye tracking measures were calculated (table 1). These measures were used as an approximation of the amount of information acquired. The number of dwells, total time, and number of options attended to are all measures of information acquired from the product shelf as a whole. The mean dwell time and the total dwell time on each product are measures of information acquired from each product specifically.

Table 1. Measures of information acquired in the different tasks, $S D$ in parentheses.

\begin{tabular}{lcc}
\hline & Decision & Search \\
\hline Total duration & $21086.4(18559.2)$ & $19706.8(15742.4)$ \\
No. of dwells & $38.64(30.73)$ & $38.80(26.80)$ \\
No. options attended to & $23.12(14.71)$ & $24.73(14.01)$ \\
$\begin{array}{l}\text { Mean dwell time on } \\
\text { each option }\end{array}$ & $550.99(142.20)$ & $533.92(170.98)$ \\
$\begin{array}{l}\text { Total dwell time on } \\
\text { each option }\end{array}$ & $893.32(328.59)$ & $783.37(262.84)$ \\
\hline
\end{tabular}

Note. All times are in ms. 
Journal of Eye Movement Research $6(1): 3,1-14$

As can be seen in table 1 , the amount of information acquired does not differ between the two tasks. Although the data do not reveal any differences between the two tasks there are other important points to observe. First, consumers only attend to a small subset of the options available in the shelf $(25.7 \%$ in the decision task and $27.5 \%$ in the search task). Second, the time in front of the shelf is quite long compared to decision times reported earlier in similar settings (Hoyer, 1984; Dickson \& Sawyer, 1990). However, the total amount of options were not reported in these studies and since they came about some years ago it is reasonably to assume that the amount have increased over the years and were not as large as in this study which included 90 different options.

Are there fewer comparisons between different products in the search task than in the decision task? To answer this question we calculated the amount of re-dwells on each product attended to. If a product was only looked at one time, the number of re-dwells was counted as zero. There was a larger amount of re-dwells in the decision task $(M=0.61, S D=0.39)$ compared to the search task $(M=0.50, S D=0.34)$, however this difference was not significant $(t(38)=0.944, p=0.17)$. A re-dwell measure of 0.5 can be interpreted as that half of the products were attended to at least twice (or that a quarter of the products received at least four re-dwells).

\section{Stages of the decision process}

As a first step we examined the presence of stages (table 2).

Table 2. Presence of stages, represented by number of participants

\begin{tabular}{|c|c|c|c|c|c|c|c|}
\hline & \multirow[b]{2}{*}{ Stage } & \multicolumn{3}{|c|}{ Search } & \multicolumn{3}{|c|}{ Decision } \\
\hline & & 1 & 2 & 3 & 1 & 2 & 3 \\
\hline NDSM & & 15 & 15 & 10 & 24 & 25 & 21 \\
\hline $\mathrm{R} \& \mathrm{~L}$ & & 15 & 14 & 10 & 25 & 23 & 21 \\
\hline
\end{tabular}

Note. NDSM refers to the Natural Decision Segmentation Model and $R \& L$ refers to the stages as proposed by Russo \& Leclerc (1994)

Given the Natural Decision Segmentation Model, the second stage will be present for all participants since it includes all dwells between the first and the last dwell on the chosen item and this item is always fixated at least once. The other stages are therefore optional. Given the
Gidlöf, K., Wallin, A., Dewhurst, R. \& Holmqvist, K. (2013) Gaze Behaviour During Decision Making in a Natural Environment

division adopted from Russo and Leclerc (1994), the first stage was the only stage present for all participants since it ended with the first re-dwell on a product. A process not including any re-dwells therefore only consisted of the first stage.

To further investigate the different stages of the decision process we calculated the proportion of the total decision time, the proportion of products attended to, and the mean dwell time in each stage (fig 3, 4 and 5). These measures describe the relative length of each stage, and how visual attention is distributed over the stages of the decision process. Each of these variables was analysed in a $2 \times 3$ mixed ANOVA crossing task (search or decision) and stage (first, second or last).

The length of each stage was normalized against the total duration of the task, which gives us the proportion of total time used to solve the task (fig. 3). There was a significant main effect of stage for both the Natural Decision Segmentation Model $(\mathrm{F}(1.4,53.5)=16.03, \mathrm{p}<$ $0.001)$ and the division adopted from Russo and Leclerc (1994) respectively $(\mathrm{F}(1.4,52.3)=44.03, \mathrm{p}<0.001)$. No interaction effects could be found between task and stage. Independent samples t-tests were used to make post hoc comparisons between the tasks. With the Natural Decision Segmentation Model, the first stage was longer in the search task and tended to significance $(M=0.54, S D$ $=0.33)$ compared to the decision task $(M=0.39, S D=$ $0.24)$ in the first stage $(t(23.2)=-1.47, \mathrm{p}=0.07)$. These results suggest that, in the search task, participants spend a longer time on other products before fixating the target product, compared to the decision task. These results are not surprising since there is only one target item in the search task compared to the decision task where several options can serve as the potential target. The differences in the other stages were not significant. No significant differences could be found between the two tasks with the division adopted from Russo and Leclerc (1994).

The number of dwells in each stage was normalized against the total number of dwells, which gives us the proportion of total number of dwells (fig. 4). There was a significant main effect of stage for both the Natural Decision Segmentation Model $(\mathrm{F}(1.6,62.4)=15.81, \mathrm{p}<$ $0.001)$ and the division adopted from Russo and Leclerc (1994) respectively $(\mathrm{F}(1.5,56.8)=26.40, \mathrm{p}<0.001)$. No interaction effects could be found between task and stage. Independent samples t-tests were used to make post hoc comparisons between the tasks but no significant diff 
Journal of Eye Movement Research $6(1): 3,1-14$

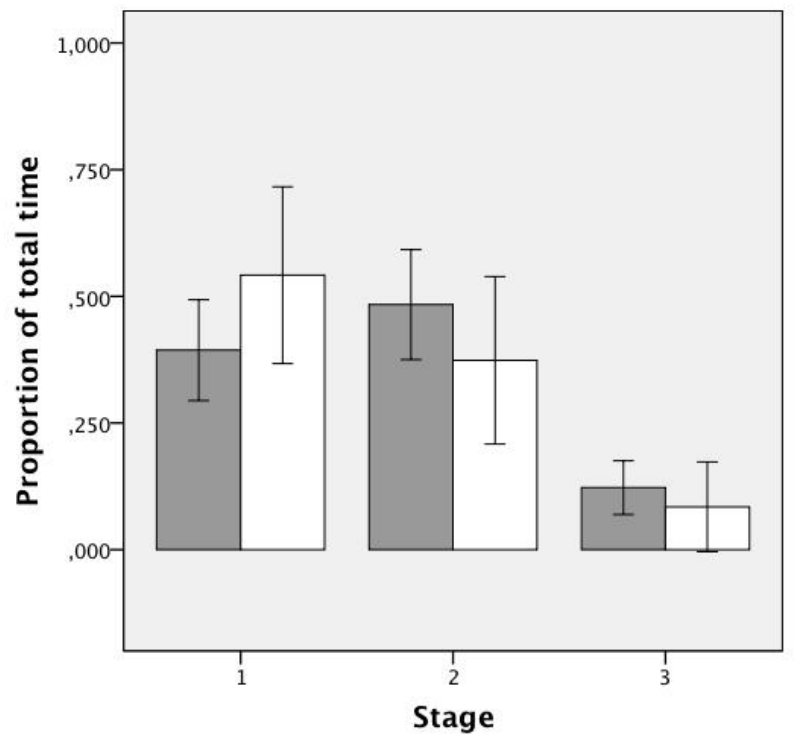

Gidlöf, K., Wallin, A., Dewhurst, R. \& Holmqvist, K. (2013) Gaze Behaviour During Decision Making in a Natural Environment

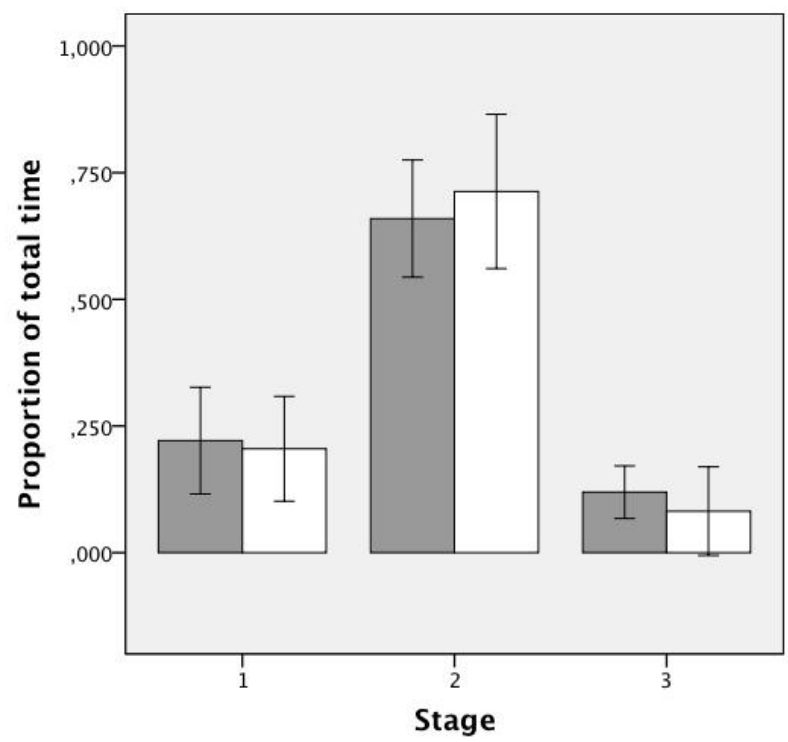

Figure 3. Proportion of total time, the Natural Decision Segmentation Model on the left, Russo and Leclerc (1994) version on the right. Grey bars represent decision task and white bars represent search task. Error bars +/- 2 SE.
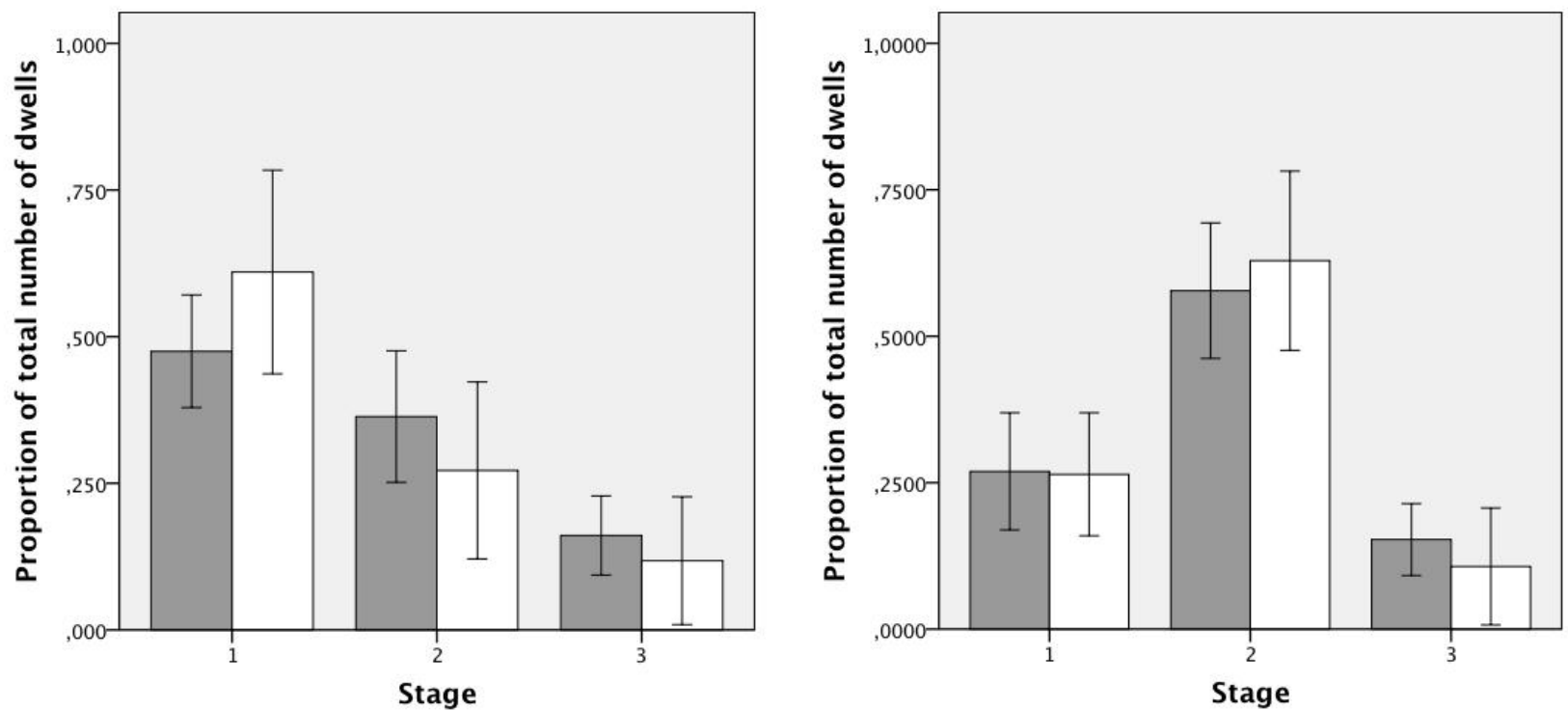

Figure 4. Proportion of total number of dwells, the Natural Decision Segmentation Model on the left, Russo and Leclerc (1994) version on the right. Grey bars represent decision task and white bars represent search task. Error bars +/- 2 SE. 

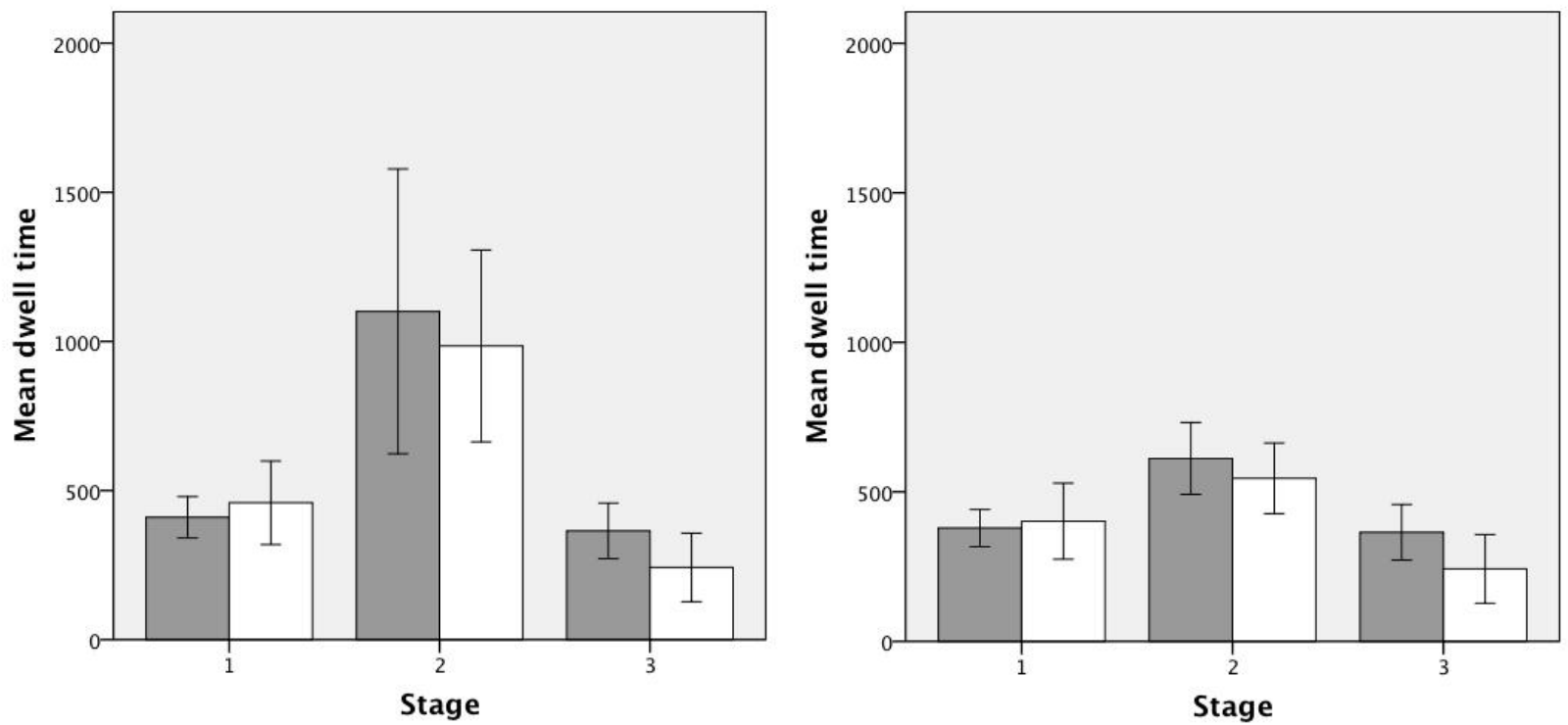

Figure 5. Mean dwell time, the Natural Decision Segmentation Model on the left, Russo and Leclerc (1994)

version on the right. Grey bars represent decision task and white bars represent search task. Error bars +/- 2 SE.

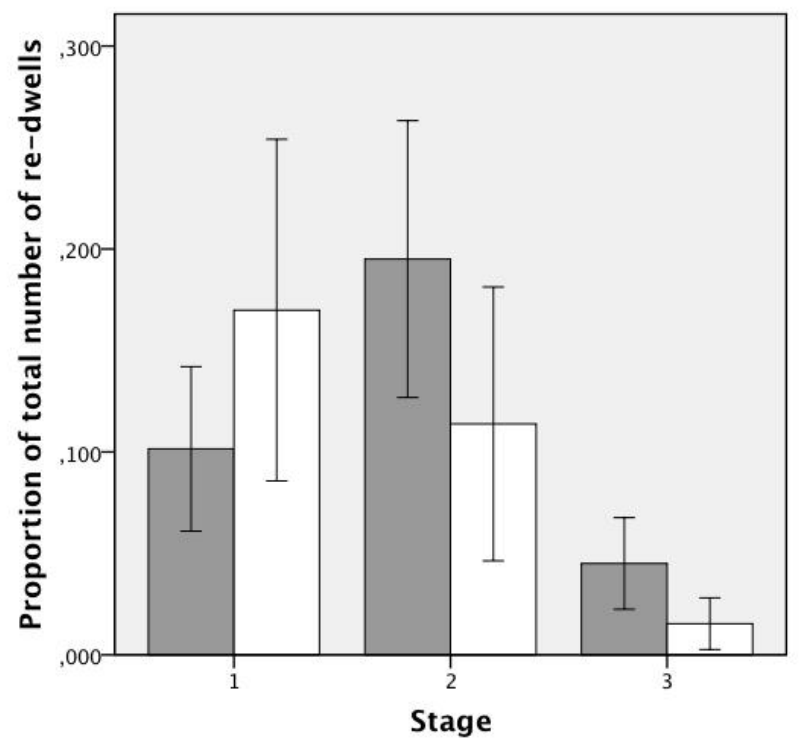

Figure 6. Proportion of total amount of re-dwells in each stage of the Natural Decision Segmentation Model.

Grey bars represent decision task and white bars represent search task. Error bars +/- 2 SE. 
Journal of Eye Movement Research $6(1): 3,1-14$

ences were found between the tasks in either of the divisions.

The mean dwell time in the different stages (fig. 5) did not differ between the two tasks, either with the Natural Decision Segmentation Model or the division adopted from Russo and Leclerc (1994). We can observe a smaller difference between the stages in the division adopted from Russo and Leclerc (1994) compared to the Natural Decision Segmentation Model. The mean dwell time in the second stage of the Natural Decision Segmentation Model is also significantly longer than the one in the division adopted from Russo and Leclerc (1994) for both the decision task $(t(24)=2.05, \mathrm{p}<0.05)$, and the search task $(t(14)=2.41, \mathrm{p}<0,05)$. This result suggests that the second stage in the Natural Decision Segmentation Model, comprising the fixations between the first and the last fixation on the chosen product, captures more of the indepth processing of the options. Interestingly, the results from the Natural Decision Segmentation Model show the opposite pattern in the frequency of dwells and dwell duration compared to Glaholt and Reingold (2011). In our data the number of dwells is higher in stage one, and dwell duration higher in stage two. Glaholt and Reingold (2011) argue that there is a bias in dwell frequency nearer the decision and that this reflects a later stage of evaluation, where participants compare between alternatives. However, what is more important than mere frequency of dwells is how these dwells are used, hence, the use of redwells are of great interest as a measure of comparison between alternatives.

For the amount of re-dwells (fig. 6), there was a significant main effect of stage $(\mathrm{F}(1.4,51.9)=9.75, \mathrm{p}<$ $0.001)$. In the second stage, there are significantly more re-dwells in the decision task compared to the search task $(t(35.6)=1.69, \mathrm{p}<0.05$, correction of degrees of freedom due to significant differences in variance between tasks) and also in the third stage $(t(35.5)=2.29, \mathrm{p}<0.05$, correction of degrees of freedom due to significant differences in variance between tasks). This implies that redwells are used differently throughout the process in the two tasks. The more pronounced use of re-dwells in the evaluation stage for the decision task might imply a greater amount of comparison between alternatives taking place in this stage compared to the search task.

Because of the differences found in the amount of redwells in the second stage between the two tasks, we decided to investigate this effect further. Since the meas-
Gidlöf, K., Wallin, A., Dewhurst, R. \& Holmqvist, K. (2013) Gaze Behaviour During Decision Making in a Natural Environment ure of amount of re-dwells does not distinguish between few dwells on many options or many re-dwells on a few options a new measure was used to tackle this issue. The proportion of products re-dwelled once, twice, three times, four times and five times was calculated for the second stage of the two tasks (fig. 7). There were a significantly larger proportion of products re-dwelled three $(t(27.6)=2.51, p<0,05$, correction of degrees of freedom due to significant differences in variance between tasks) and four times $(\mathrm{t}(24)=2.39, \mathrm{p}<0,05$, correction of degrees of freedom due to significant differences in variance between tasks) for the decision task compared to the search task. This means that the difference in amount of re-dwells in the second stage between the decision task and the search task is due to a larger amount of re-dwells back to the same product for participants who performed the decision task. To note here is that $40 \%$ of all participants who performed the decision task made 3 or more re-dwells back to the same product compared to $13 \%$ of participants who performed the search task.

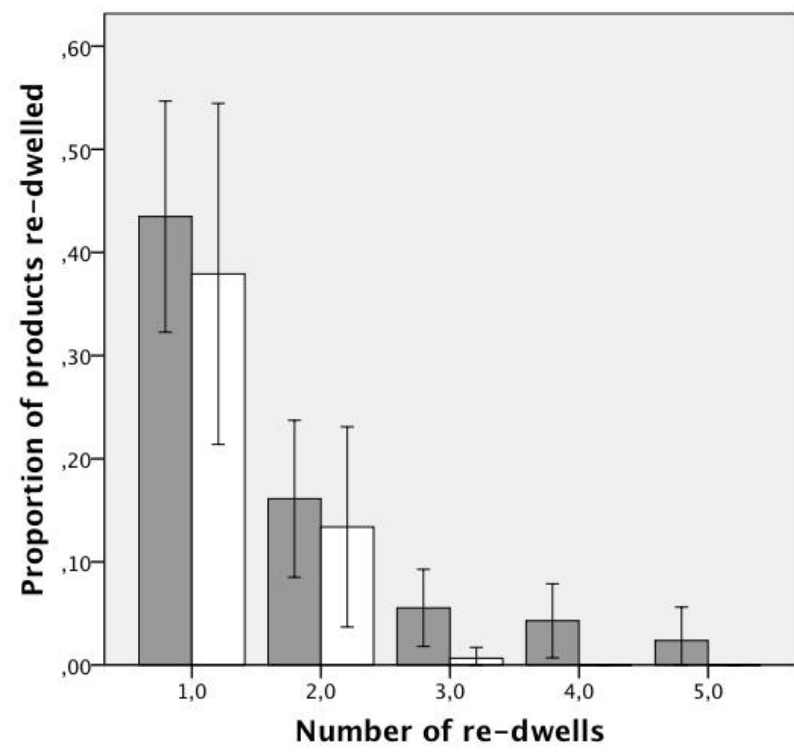

Figure 7. Proportion of products re-dwelled once, twice and so forth in the second stage of the Natural Decision Segmentation Model. Grey bars represent decision task and white bars represent search task. Error bars +/- 2 SE. 
Journal of Eye Movement Research

$6(1): 3,1-14$

\section{Discussion}

\section{What we observed}

As can be observed in figure 3, 4 and 5, there are general differences between the Natural Decision Segmentation Model and the one adopted from Russo and Leclerc (1994). With the division adopted from Russo and Leclerc (1994), the process is dominated by stage 2, the evaluation stage, in respect to all measures and for both the decision and the search task. This may not be surprising considering that this second stage begins with the first re-dwell on a product previously attended to. The Natural Decision Segmentation Model seems to better capture the more in-depth processing of the alternatives in the evaluation stage since the dwell times in the second stage are significantly longer than in the division adopted from Russo and Leclerc (1994). These results are contrary to previous findings in the lab (e.g. Glaholt, $\mathrm{Wu} \&$ Reingold, 2010) where participants' dwells are longer and indicate orienting at the start (cf. stage 1), while dwell frequency is higher later on reflecting evaluation.

More importantly it is only with the Natural Decision Segmentation Model that a difference can be found between the search and the decision task, namely the amount of re-dwells in the second and in the third stage. It is noteworthy that aggregate data describing task duration, number of dwells, no of options attended to etc. did not differentiate between the search and decision tasks. What seems to be the most characteristic feature of decision-making is in the use of re-fixations or re-dwells throughout the process. The difference in re-dwells, with a higher number in the second stage of the decision task is noteworthy since re-dwells seem to be at the core of the decision process. This is, of course, why Russo and Leclerc (1994) used it to define the evaluation stage, but we believe this is mistaken for two reasons. First, as we have already indicated, re-dwells play other important roles in visual attention (for instance, we observe a relatively high number of re-dwells in the search task). Second, Russo and Leclerc's way to define the stages made it impossible to differentiate the search and decision task. The operationalization did not target sufficiently unique features of the decision process.

The results for the search task might seem surprising considering the observed behaviour in the second stage e.g. all dwells between the first and last dwell on the target item. Participants spend a considerable amount of
Gidlöf, K., Wallin, A., Dewhurst, R. \& Holmqvist, K. (2013) Gaze Behaviour During Decision Making in a Natural Environment time and the longest dwells in this stage although at this point, the target item was already dwelled upon once. These results support our claim that the supermarket is a very complex environment and that search for a product in this kind of natural situation is more difficult than in regular search tasks and demands more visual processing.

\section{Relation to previous research}

There seems to be an overestimation of the second stage in the division adopted from Russo and Leclerc (1994). Clearly, using re-dwells to separate the stages is not the way to go in complex real world settings. Note that no differences between tasks were found in the Russo and Leclerc (1994) framework although differences between stages were found. This demonstrates the need for a comparison task (akin to a null-hypothesis), which allows us to evaluate the process tracing method.

There is a growing area of research studying visual attention in natural environments. Even more than most cognitive processes, eye movements are deeply affected by the structure of the task environment - and the vision research community is painfully aware of its reliance on overly structured and information scarce tasks. Unlike other cognitive tasks previously studied with eye tracking, in a decision making task it is not interesting to compare WHAT different participants visually attend to since the same item can have a completely different meaning for different participants. One and the same product can be the optimal choice for one participant but not even a considerable option for another. This means we need a new set of measures or analysing tools to study this kind of process.

Our approach of dividing the decision process into separate stages, the Natural Decision Segmentation Mod$\mathrm{el}$, can serve as this new tool tracing decision processes in natural environments. Unlike the division adapted from Russo and Leclerc (1994) it can not only separate the features that distinguish a search process from a decision process, namely re-dwells, but also better understand the use of re-dwells throughout the process. We agree with Russo and Leclerc (1994) that re-dwells are an important feature of the evaluation stage. However, re-dwells serve several important other purposes such as returning to complete processing of an item. It is thus important to study them during the other stages as well, for instance, as a measure of search and task difficulty. 
Journal of Eye Movement Research

$6(1): 3,1-14$

In conclusion, our study continues the new tradition of studying eye movements and visual attention in natural environments. To some extent it replicates the findings of previous decision-making research, looking at the visual attention during choice, with an initial screening process followed by a stage in which options are processed at greater depth. Our study extends this research by observing the functional stages of a decision process and also comparing it to a search process. We have seen that these processes share common features but are separated by the use of re-dwells through out the process.

\section{References}

Ballard, D. H., \& Hayhoe, M. M. (2009). Modelling the role of task in the control of gaze. Visual Cognition, $17,1185-1204$

Bettman, J. R., \& Park, C. W. (1980). Effects of Prior Knowledge and Experience and Phase of the Choice Process on Consumer Decision Processes: A Protocol Analysis. Journal of Consumer Research, 7, 234-248

Born, S., Kerzel, D., \& Theeuwes, J. (2011). Evidence for a dissociation between the control of oculomotor capture and disengagement. Experimental Brain Research, 208, 621-631

Castelhano, M. S., Mack, M. L., \& Hendersson, J. M. (2009). Viewing task influences eye movement control during active scene perception. Journal of Vision, 9, $1-15$

Chandon, P., Hutchinson, J. W., Bradlow, S. H., \& Young, E. (2009). Does In-StorMarketing Work? Effects of the Number and Position of Shelf Facings on Brand Attention and Evaluation at the Point of Purchase. Journal of Marketing, 73, 1-17.

Chernev, A. (2003) When more is less and less is more: the role of ideal point availability and assortment in consumer choice. Journal of Consumer Research, 30, $170-183$

DeAngelus, M., \& Pelz, J. B. (2009). Top-down control of eye movements: Yarbus revisited. Visual cognition, $17,790-811$

Dickson, P. R., \& Sawyer, A. G. (1990). The Price Knowledge and Search of Supermarket Shoppers. Journal of Marketing, 54, 42-53
Gidlöf, K., Wallin, A., Dewhurst, R. \& Holmqvist, K. (2013) Gaze Behaviour During Decision Making in a Natural Environment

Duncan, J., \& Humphreys, G. W. (1989). Visual search and stimulus similarity. Psychological Review, 96, $433-458$

Findlay, J. M., Brown, V., \& Gilchrist, I. D. (2001). Saccade target selection in visual search: the effect of information from the previous fixation. Vision Research, 41, 87-95

Ford, J. K., Schmitt, N., Schechtman, S. L., Hults, B. M., \& Doherty, M. L. (1989). Process tracing methods: Contributions, problems, and neglected research questions. Organizational Behavior and Human Decision Processes, 43, 75-117

Foulsham, T., \& Kingstone, A. (2012). Goal-driven and bottom-up gaze in an active real-world search task. In Spencer, S. N. (Ed.) Proceedings of the Symposium on Eye Tracking Research and Applications (ETRA '12) ACM, New York, NY, USA, 189-192.

Foulsham, T., Walker, E., \& Kingstone, A. (2011). The where, what and when of gaze allocation in the lab and the natural environment. Vision Research, 51, 1920-1931

Gilchrist, I. D., \& Harvey, M. (2000). Refixation frequency and memory mechanisms in visual search. Current Biology, 10, 1209-1212

Glaholt, M. G., \& Reingold E. M. (2009). The time course of gaze bias in visual decision tasks. Visual Cognition, 17, 1228-1243

Glaholt, M. G., \& Reingold E. M. (2011). Eye Movement Monitoring as a Process Tracing Methodology in Decision Making Research. Journal of Neuroscience, Psychology, and Economics, 4, 125-146

Glaholt, M. G., Wu, M-C., \& Reingold, E. M. (2010). Evidence for top-down control of eye movements during visual decision making. Journal of Vision, 10, $1-10$

Hayhoe, M. M., \& Ballard, D. H. (2005). Eye movements in natural behavior. Trends in Cognitive Sciences, 9, 188-194

Hoyer, W. D. (1984). An Examination of Consumer Decision Making for a Common Repeat Purchase Product. Journal of Consumer Research, 11, 822-829

Iyengar, S. S., \& Lepper, M. R. (2000). When choice is demotivating: can one desire too much of a good thing? Journal of Personality and Social Psychology, 79, 995-1006 
Journal of Eye Movement Research

$6(1): 3,1-14$

Jovanevic-Misic, J., \& Hayhoe, M. M. (2009) Adaptive Gaze Control in Natural Environments. Journal of Neuroscience, 29, $6234-6238$

Just, M. A., \& Carpenter, P. A. (1985). Cognitive Coordinate Systems: Accounts of Mental Rotation and Individual Differences in Spatial Ability. Psychological Review, 92, 137-172

Kingstone, A., Smilek, D., \& Eastwood, J. D. (2008). Cognitive Ethology: A new approach for studying human cognition. British Journal of Psychology, 99, 317-340.

Krajbich, I., Armel C., \& Rangel, A (2010). Visual fixations and the computation and comparison of value in simple choice. Nature Neuroscience, 13, 1292-1298

Krajbich, I., \& Rangel, A (2011). Multialternative driftdiffusion model predicts the relationship between visual fixations and choice in value-based decisions. PNAS, 108, 13852-13857

Land, M. F., \& McLeod, P. (2000). From eye movements to actions: how batsmen hit the ball. Nature Neuroscience 3, 1340-1345

Land, M. F., Mennie, N., \& Rusted, J (1999). The roles of vision and eye movements in the control of activities of daily living. Perception, 28, 1311-1328

Lohse, G. L., \& Johnson, E. J. (1996). A comparison of two process tracing methods for choice tasks. Organizational Behavior and Human Decision Processes, $68,28-43$

Malcolm, G. L., \& Henderson, J. L. (2009). The effects of target template specificity on visual search in realworld scenes: Evidence from eye movements. Journal of Vision, 9, 1-13

Malcolm, G. L., \& Henderson, J. L. (2010). Combining top-down processes to guide eye movements during real-world scene search. Journal of Vision, 10, 1-11

Malhotra, N. K. (1982). Information load and consumer decision making. Journal of Consumer Research, 8, 419-430

McSorley, E., \& Findlay, J. M. (2003). Saccade target selection in visual search: Accuracy improves when more distractors are present. Journal of Vision, 3, 877-892

Mulckhuyse, M., Van Zoest, W., \& Theeuwes, J. (2008). Capture of the eyes by relevant and irrelevant onsets. Experimental Brain Research, 186, 225-235.
Gidlöf, K., Wallin, A., Dewhurst, R. \& Holmqvist, K. (2013) Gaze Behaviour During Decision Making in a Natural Environment

Payne, J. W. (1976). Task complexity and contingent processing in decision making: an information search and protocol analysis. Organizational Behavior and Human Performance, 16, 366-387.

Payne, J. W., Bettman, J. R., \& Johnson, E. J. (1988). Adaptive strategy selection in decision making. Journal of experimental Psychology: Learning, Memory, and Cognition, 14, 534-552.

Payne, J. W., Bettman, J. R., \& Johnson, E. J. (1993). The Adaptive Decision Maker. Cambridge: Cambridge University Press

Payne, J. W., Braunstein, M. L., \& Carroll, J. S. (1978). Exploring Predecisional Behavior: An Alternative Approach to Decision Research. Organizational Behavior and Human Performance, 22, 17-44

Pieters, R., \& Warlop, L. (1999). Visual attention during brand choice: The impact of time pressure and task motivation. International Journal of Research in Marketing, 16, 1-16

Reisen, N., Hoffrage, U., \& Mast, F. W. (2008). Identifying decision strategies in a consumer choice situation. Judgment and Decision Making, 3, 641-658

Reutskaja, E., \& Hogarth, R. M. (2005). Satisfaction in choice as a function of the number of alternatives: when "goods satiate". Psychology \& Marketing, 26, 197-203

Russo, J. E., \& Leclerc, F. (1994). An eye-fixation analysis of choice processes for consumer nondurables. Journal of consumer research, 21, 274-290

Russo, J. E., \& Rosen, L. D. (1975). An eye fixation analysis of multialternative choice. Memory and Cognition, 3, 267-276

Shah, A. M., \& Wolford, G. (2007). Buying behavior as a function of parametric variation of number of choices. Psychological Science, 18, 369-370

Schotter, E. R., Berry, R. W., McKenzie, C. R. M., \& Rayner, K. (2010). Gaze bias: Selective encoding and liking effects. Visual Cognition, 18, 1113-1132

Shimojo, S., Simion, C., Shimojo, E., \& Scheier, C. (2003). Gaze bias both reflects and influences preference. Nature Neuroscience, 6, 1317-1322

Shinoda, H., Hayhoe, M. M., \& Shrivastava, A. (2001). What controls attention in natural environments? $\mathrm{Vi}$ sion Research, 41, 3535-3545 
Simion, C., \& Shimojo, S. (2006). Early interactions between orienting, visual sampling and decision making in facial preference. Vision Research, 46, 33313335

Smilek, D., Eastwood, J. D., Reynolds, M. G., \& Kingstone, A. (2007). Metacognition and change detection: Do lab and life really converge? Consciousness and Cognition, 17, 1056-1061

Treisman, A., \& Gormican, S. (1988). Feature analysis in early vision: Evidence from search asymmetries. Psychological Review, 95, 15-48

Van Raaij, W. F. (1977). Consumer information processing for different information structures and formats. Advances in Consumer Research, 4, 176-184.

Vlaskamp, B. N. S., \& Hooge, I. Th. C. (2006). Crowding degrades saccadic search performance. Vision Research, 46, 417-425

Wedell, D. H., \& Senter, S. M. (1997). Looking and Weighting in Judgment and Choice. Organizational Behavior and Human Decision, 70, 41-64

Yarbus I. A. (1967). Eye Movements and Vision. New York: Plenum 